\title{
O ENSINO DE PRINCÍPIOS DE ECONOMIA: UMA CONTRIBUIÇÃO
}

\author{
SOLANGE DE CASSIA INFORZATO DE SOUZA *
}

\section{SOUZA, S.C.I. de O ensino de princípios de economia: uma contribuição. Semina: Ci.}

Sociais/Humanas, Londrina, v. 17, n. 3, p. 329-337, set. 1996.

RESUMO: O objetivo deste trabalho é o de provocar uma reflexão sobre o ensino de princípios de economia, através da análise de dois elementos fundamentais que constituem o processo inicial de formação do economista. A partir da realidade da UEL, discute o perfil do calouro de economia e caracteriza o docente que transmite o conhecimento econômico introdutório, buscando experiências concretas em escolas de economia do país. Conclui que docentes que atuam na disciplina devem ser anteriormente contemplados pela preparação teórica e pedagógica, pelo conhecimento profundo da dimensão da realidade discente, e por programas e ações integradas desenvolvidos para esse fim.

PALAVRAS-CHAVE: Ensino de economia; principios de economia; calouro de economia; professor de economia.

\section{INTRODUÇĀO}

Problemas econômicos como o desemprego, o déficit comercial, a inflação e o déficit público fazem parte das discussões diárias dos brasileiros. Anteriormente confinados à comunicação dos economistas, os conceitos econômicos passarama incorporar o linguajar comum da população, evidenciando o quanto a economia impregna a vida da sociedade brasileira.

Quando GALBRAITH (1992) afirma que "entender o funcionamento da economia é entender a maior parte de nossa vida", ou "uma compreensão da econo-

* Departamento de Economia/Universidade Estadual de Londrina, Caixa Postal 6001, Londrina, PR, CEP 86051-990.

A autora agradece a colaboração da professora Rossana Lott Rodrigues durante a investigaçäo, isentando-a da responsabilidade sobre as opiniões aqui emitidas. 
mia é uma compreensão da principal preocupação da vida", percebe-se a magnitude da ciência econômica, tornando-se importante saber o que ela tem para oferecer em termos de explicação dos fenômenos econômicos e, principalmente, o papel desempenhado pelo profissional da economia em uma realidade na qual ele se transformou no centro das grandes decisões e que deve estar pronto para responder aos desafios da nação.

Sendo assim, o ensino formal da economia apresenta-se da maior relevância, e uma reflexão sobre a qualidade do profissional que está em formação em fun-

- ção de sua atuação dentro da comunidade brasileira é urgente. Esta preocupação aprofundou-se com a abertura da nova fase do ensino das ciências econômicas no país pela reforma curricular de 1984 .

Resultado de mais de uma década de discussões e esforços em favor de uma alternativa para o currículo anterior (o de 1962), o novo currículo mínimo (o de 1984) para os cursos de graduação em economia do país destaca pontos importantes. Em primeiro lugar, a necessidade de dar ênfase à formação teórica sólida ao invés de pretender concentrar o curso unicamente em aspectos práticos da realidade econômica. Por outro lado, foi consensual a idéia de proporcionar o conhecimento adequado do quadro histórico-institucional em que se insere a realidade à qual se aplicam as abstrações teóricas, principalmente o reforço da formação institucional e econômica do Brasil. (CONSELHO... 1984)

Em segundo lugar, o bacharelado em ciências econômicas inovou com a inserção da monografia como requisito de graduação, buscando um treinamento na redação de trabalhos escritos e exposição de argumentos de maneira articulada e formalmente correta. Ademais, manifestou-se a intenção de se abrir espaço para abordagens alternativas, tentando uma orientação menos ortodoxa para o ensino da teoria. (VERSIANI, 1984) A nova etapa no ensino de economia, inaugurada na segunda metade da década de 80 e que se estende até nossos dias, procura menos ignorar o pluralismo de ideias, mas antes garantir a sua diversidade, devendo incorporar as modificações ocorridas no decorrer dos anos, tanto no plano teórico quanto prático. (KIPNIS, 1980, 1981).

E, nesse caminho, o processo de ensino-aprendizagem da economia tem gerado debates e indagações em escolas do país, conforme demonstram BASTOS [198_], CASTRO (1988), GANEN [198_] e LEME (1986). Na Universidade Estadual de Londrina - UEL, passados onze anos da implantação do novo currículo, e a inauguração do sistema seriado em 1992, colocouse a necessidade de repensar o ensino da economia. $O$ curso introdutório foi escolhido para que se buscasse algumas contribuições para a melhoria da qualidade do seu ensino, e a partir daí essas discussões se extrapolassem para as demais disciplinas do curso.

A disciplina introdutória em economia tem uma fração significativa no curso de economia. Ela significa que o primeiro contato do aluno para com a ciência econômica, representando, na UEL, $20 \%$ do total de carga horária do primeiro ano de estudo e $67 \%$ do total de carga horária oferecida pelo departamento de economia no primeiro ano de curso.

É ponto pacífico a idéia de que o "pluralismo, ao nível da introdução à economia, significa transmitir ao estudante, desde o início, a idéia de que a economia é ciência social, sem qualquer parentesco próximo ou distante com as chamadas ciências exatas, e enquanto social é política, comportando visões diferenciadas sobre os problemas econômicos, algumas excludentes e outras não". (BUAINAIN, [198_]) No entanto, a tarefa de discutir alternativas de organização para um curso introdutório dentro de uma perspectiva de avanços e reformulações é muito árdua, principalmente quando não se tem muito claro o perfil do discente que irá absorvêlo e nem do docente que se responsabiliza em ministrálo. É nesse sentido que este trabalho avança, atentando-se para o aluno que inicia o curso de economia e tem sua primeira aproximação à ciência econômica através da disciplina de introdução à economia, e do professor que a tem sob sua responsabilidade.

Nesse sentido, há que se questionar se o domínio do conhecimento é condição suficiente para que o docente ministre esse curso. Qual é, ou deve ser, o perfil do professor empenhado a ensinar os primeiros passos da economia? Aquele que acaba de se inserir na carreira universitária, sem titulação acadêmica, pois a idéia seria a de que a cadeira não exige muito conhecimento e as questões levantadas na sala de aula são, de forma geral, despidas de rigor tanto nas formulações quanto nas exigências de respostas mais elaboradas? Ou, pelo contrário, é, ou deve ser, o profissional experiente e titulado, para que seja depositado nele a incumbência de instigar 0 aluno, de estimulá-lo, e de provocálo porque é um profundo conhecedor do curso como um todo? E quanto ao método de ensino, terá havido um padrão de procedimentos didático-pedagógicos que contemple o ensino e a aprendizagem concomitantemente?

Diante dessa problemática, este trabalho procura apresentar uma contribuição ao ensino de princípios de economia, através da observação das condições em que está submetido o processo inicial de formação do economista. Especificamente, objetiva-se traçar o perfil do calouro de economia da UEL, e apresentar as características do professor de introdução à economia que atua em instituições públicas, aspectos de formação acadêmica e experiência profissional, além de seus conhecimentos didático-pedagógicos, comparando-as com o caso da UEL. 


\section{METODOLOGIA}

A investigação foi realizada no período compreendido entre março de 1994 e dezembro de 1995, tendo sofrido interrupção no primeiro semestre de 1995; e, para a sua consecução, realizou-se por conta de dois aspectos. Primeiro, o levantamento de informações básicas relativas ao discente, calouro em economia, que tem o primeiro contato com a ciência econômica através da disciplina de princípios de economia. Para isto, foram aplicados 100 questionários na UEL. O instrumento levou em conta a identificação pessoal, formação escolar, acadêmica e profissional do aluno.

Segundo, a caracterização do profissional que transmite o conhecimento econômico introdutório. A partir da realidade da UEL, buscou-se a experiência das demais escolas de economia do país, públicas estaduais e federais, num total de 51 unidades de ensino para subsidiar a análise. A técnica utilizada foi a pesquisa direta por questionário, enviados via Correios. Além disso, um estudo documental foi tentado para que permitisse analisar o conteúdo, as estratégias de ensino aplicadas e o processo de avaliação escolhido.

Do cronograma proposto tem-se algumas observações a serem feitas. O questionário referente ao perfil do calouro foi elaborado nos meses de março e abril/ 94 , testado e reformulado em maio/94, e aplicado em junho/94.

De junho a meados de setembro de 1994 foram confeccionados os instrumentos "perfil do docente que leciona introdução à economia para o curso de economia", e "conhecimentos e procedimentos didático-pedagógicos", direcionados para o mesmo público, o professor de introdução à economia.

A coleta de informações através desses questionários iniciou-se em outubro/94, tendo sido remetidos, através dos Correios, 05 (cinco) para a região norte do país, 18 (dezoito) para a região nordeste, 05 (cinco) para a região centro-oeste, 14 (quatorze) para a sudeste, e 09 (nove) para a região sul. As dificuldades encontradas para obter as respostas levaram então a uma ampliação do prazo para recebimento dos instrumentos de pesquisa, que durou até março/95. Conforme mencionado, o trabalho foi interrompido no primeiro semestre de 1995 e reiniciado em julho do mesmo ano, com nova dilação de prazo para as respostas, dezembro/95, período em que novamente foram mantidos contatos com as instituições não respondentes. Apesar de todos os esforços e tentativas, a equipe recebeu 15 (quinze) questionários dos 51 (cinqüenta e um) remetidos, ou seja, $29,4 \%$ do total.

É preciso esclarecer também que a demanda universitária pela introdução à economia é formada por alunos do curso de economia e por alunos de outros cursos nos quais a disciplina faz parte de seus currículos. Na UEL, há uma diferença de nomenclatura, dirigindo a expressão introdução à economia para a disciplina oferecida aos outros cursos e princípios de economia somente para o curso de economia. Este trabalho concentra a análise no ensino da disciplina especificamente para o curso de economia, utilizando, indistintamente, as expressões introdução e princípios de economia.

\section{RESULTADOS E DISCUSSÕES}

\subsection{Elementos para a configuração da realidade da formação inicial do economista}

\subsubsection{Características do primeiroanista}

Para a apreensão da realidade do aluno que tem o primeiro contato com a ciência econômica através da disciplina introdutória de economia, foram aplicados 100 questionários em três turmas de princípios de economia da UEL, obtendo, no noturno, 67 respostas, e no matutino, 33 respostas, representando $83 \%$ do total de alunos matriculados na disciplina.

As respostas obtidas foram reunidas nos seguintes grupos: grupo 1 - identificação pessoal, grupo 2 procedência residencial e formação escolar e profissional dos pais, grupo 3 - formação educacional, e, grupo 4 - situação profissional do aluno.

Pelo grupo 1 percebe-se que $61 \%$ dos calouros de economia têm entre 16 e 21 anos, $64 \%$ são do sexo masculino, e $90 \%$ são solteiros. Com exceção do estado civil, a análise toma outra forma se diferenciarmos segundo o turno em que frequentam o curso. No noturno, a diferença é menos significativa entre os alunos menores de 21 anos $(52,2 \%)$ e os de 22 a 27 anos $(41,8 \%)$. Ao contrário do matutino, em que $78,8 \%$ tem entre 16 e 21 anos, ficando com apenas $18,2 \%$ os alunos que têm entre 22 e 27 anos. Quanto ao sexo, a diferença fica destacada no noturno, onde $74,6 \%$ são homens, contra $25,4 \%$ de mulheres, enquanto no matutino, esta não se manifesta tão fortemente, sendo $42,4 \%$ e $57,6 \%$, respectivamente, homens e mulheres.

No grupo 2, procedência residencial e formação escolar e profissional dos pais, observa-se que $48 \%$ dos alunos vêm de Londrina e $49 \%$ de outras cidades do Paraná e interior de São Paulo. (Tabela 1) Em termos de formação escolar dos pais, menos de $20 \%$ dos pais dos alunos questionados tem curso superior completo, estando as mães dedicadas ao lar (aproximadamente $60 \%$ ), e apenas $19,8 \%$ dos pais como profissionais liberais. 
TABELA 1 - Identificação pessoal do calouro de economia

\begin{tabular}{|c|c|c|c|c|c|c|}
\hline \multirow{2}{*}{$\begin{array}{l}\text { Dados } \\
\text { Pessoais }\end{array}$} & \multicolumn{2}{|l|}{ Matutino } & \multicolumn{2}{|l|}{ Noturno } & \multicolumn{2}{|l|}{ TOTAL } \\
\hline & № & $\%$ & $\mathrm{~N}^{\mathrm{o}}$ & $\%$ & № & $\%$ \\
\hline Idade & 33 & 100,00 & 67 & 100,00 & 100 & 100,00 \\
\hline 16 a 21 anos & 26 & 78,80 & 35 & 52,20 & 61 & 61,00 \\
\hline 22 a 27 anos & 6 & 18,20 & 28 & 41,80 & 34 & 34,00 \\
\hline 28 a 33 anos & 1 & 3,00 & 3 & 4,50 & 4 & 4,00 \\
\hline mais de 33 anos & - & - & 1 & 1,50 & 1 & 1,00 \\
\hline Sexo & 33 & 100,00 & 67 & 100,00 & 100 & 100,00 \\
\hline Masculino & 14 & 42,40 & 50 & 74,60 & 64 & 64,00 \\
\hline Feminino & 19 & 57,60 & 17 & 25,40 & 36 & 36,00 \\
\hline Estado Civil & 33 & 100,00 & 67 & 100,00 & 100 & 100,00 \\
\hline Solteiro & 29 & 87,90 & 61 & 91,00 & 90 & 90,00 \\
\hline Casado & 4 & 12,10 & 5 & 7,50 & 9 & 9,00 \\
\hline Divorciado & - & - & 1 & 1,50 & 1 & 1,00 \\
\hline Procedência & 33 & 100,00 & 67 & 100,00 & 100 & 100,00 \\
\hline Londrina & 11 & 33,30 & 37 & 55,20 & 48 & 48,00 \\
\hline Outras cidades PR & 9 & 27,30 & 18 & 26,90 & 27 & 27,00 \\
\hline Interior de S. Paulo 1 & 12 & 36,40 & 10 & 14,90 & 22 & 22,00 \\
\hline Outras cidades & 1 & 3,00 & 2 & 3,00 & 3 & 3,00 \\
\hline
\end{tabular}

Fonte: Pesquisa direta com questionário - UEL/94

O grupo 3 abrangeu um número maior de perguntas, procurando sondar a formação educacional do calouro em termos de tempo passado entre a conclusão do $2^{\circ}$ grau e o início do curso de graduação, subordinação administrativa da escola em que cursou o $2^{2}$, turno frequentado, cursinhos preparatórios de vestibular realizados, e o número de vestibulares prestados.

Pelas respostas conseguidas, $61 \%$ dos calouros completaram o $2^{\circ}$ grau entre 1991 e 1992 , tendo $57 \%$ frequentado escola pública e $53 \%$ no periodo diurno. Com exceção da dependência administrativa da escola de $2^{\circ}$ grau frequentada, os dados referentes ao ano de conclusão do $2^{\circ}$ grau e turno diferenciam-se muito nos dois turnos pesquisados na graduação, o que não é surpreendente. No matutino, por exemplo, $81,8 \%$ dos alunos tem concluído o $2^{\circ}$ grau recentemente, ao passo que no noturno este número desce para $50,7 \% ; 66,7 \%$ dos alunos de graduação do matutino fizeram o $3^{\circ}$ ano do $2^{\circ}$ grau no período diurno, e, ao contrário, $46,3 \%$ dos estudantes da graduação noturno o fizeram durante a manhã ou tarde. Outro ponto está na frequência aos cursinhos preparatórios de vestibular; em torno de $56 \%$ dos calouros o fizeram.

Isso tudo sugere que aproximadamente metade dos estudantes que vinham do $2^{\circ}$ grau diurno, avançam para a profissão de economista, cursando à noite para ter oportunidade de trabalho e estágios durante o dia. Por outro lado, há que se levar em conta as especificidades do aluno noturno que, embora tenha terminado o $2^{\circ}$ grau em tempo que não se distancia muito do início da graduação, vem de escola pública noturna. (Tabela 2) A opção pelo curso noturno de economia, enquanto modalidade de oferta do ensino universitário, é uma alternativa de ingresso e permanência face à própria conjuntura sócio-econômica do país. 
TABELA 2 - Formação educacional do calouro de economia

\begin{tabular}{|c|c|c|c|c|c|c|c|c|c|c|c|c|c|c|c|c|c|}
\hline \multirow[t]{3}{*}{ Turno } & \multicolumn{7}{|c|}{ Conclusão do $2^{9}$ grau } & \multicolumn{5}{|c|}{$\begin{array}{l}\text { Instituição que cursou o } \\
3^{\circ} \text { ano do } 2^{\circ} \text { grau }\end{array}$} & \multicolumn{5}{|c|}{$\begin{array}{l}\text { Turno que cursou } \\
3^{\circ} \text { ano do } 2^{\circ} \text { grau }\end{array}$} \\
\hline & \multicolumn{2}{|c|}{$\begin{array}{l}\text { antes } \\
1984\end{array}$} & \multicolumn{2}{|c|}{$1985-90$} & \multicolumn{2}{|c|}{$1991 \cdot 95$} & \multirow[b]{2}{*}{ total } & \multicolumn{2}{|c|}{ Pública } & \multicolumn{2}{|c|}{ Privada } & \multirow[b]{2}{*}{ total } & \multicolumn{2}{|c|}{ Diurno } & \multicolumn{2}{|c|}{ Noturno } & \multirow[b]{2}{*}{ total } \\
\hline & № & $\%$ & $\mathrm{~N}$ & $\%$ & N & $\%$ & & $N$ & $\%$ & $\mathrm{~N}$ & $\%$ & & $\mathrm{~N}$ & $\%$ & $N$ & $\%$ & \\
\hline Mat. & 1 & 3 & 5 & 15,2 & 27 & 81,8 & 33 & 19 & 57,6 & 14 & 42,4 & 33 & 22 & 66,7 & 1 & 33,3 & 33 \\
\hline Not. & 5 & 7,5 & 2,8 & 41,8 & 34 & 50,7 & 67 & 38 & 57,6 & 29 & 43,3 & 67 & 31 & 46,3 & 36 & 53,7 & 67 \\
\hline Total & 6 & & 33 & & 61 & & 100 & 57 & & 43 & & 100 & 53 & & 47 & & 100 \\
\hline$\%$ & 100 & & 33 & & 61 & & 100 & 57 & & 43 & & 100 & 53 & & 47 & & 100 \\
\hline
\end{tabular}

Fonte: Pesquisa direta com questionário. UEL/94

Preocupante são os dados sobre a escolha pelo curso de economia. Apesar de mais de $80 \%$ dos alunos terem prestado o vestibular para economia uma única vez, $61 \%$ deles já havia tentado outros cursos anteriormente; se a análise se partir por turnos, $63,6 \%$ e $59,7 \%$, matutino e noturno respectivamente. A economia, para esses alunos é uma opção após terem sido frustradas as tentativas anteriores para outras profissões. Isto revela um assunto delicado que deve ser tratado como tal. Em seu primeiro contato com o curso, o calouro deve começar a perceber a ciência econômica com cla- reza e método, para que possa dar respaldo à sua "opção", ou não. A forma de encaminhar na iniciação econômica um aluno que fez sua primeira escolha é diferente daquela que deve ser perseguida pelos alunos que fazem o curso com $2^{\mathrm{a}}$ ou $3^{\mathrm{a}}$ escolha. Por certo o caminho que percorrerão, pelo menos até tomarem o gosto pela economia, será mais árduo e de dificuldades. A responsabilidade pelo ensino de cadeiras básicas é fundamental para o prosseguimento ou não no curso. (Tabelas 3 e 4)

TABELA 3 - Tentativas de concurso vestibular para economia dos calouros de economia

\begin{tabular}{lcccrcc}
\hline № de Tentativas & \multicolumn{2}{c}{ № Absoluto } & \multicolumn{2}{c}{$\%$} & \multicolumn{2}{c}{ TOTAL } \\
& Matutino & Noturno & Matutino & Noturno & № & $\%$ \\
\hline Uma única vez & 30 & 55 & 90,90 & 82,10 & 85 & 85,00 \\
Duas vezes & 3 & 11 & 9,10 & 16,40 & 14 & 14,00 \\
3 ou mais vezes & - & 1 & - & 1,50 & 1 & 1,00 \\
TOTAL & 33 & 67 & 100,00 & 100,00 & 100 & 100,00 \\
\hline
\end{tabular}

Fonte: Pesquisa direta com questionário. UEL/94

TABELA 4 - Tentativas de concurso vestibular para outros cursos

\begin{tabular}{lllllll}
\hline № de Tentativas & \multicolumn{2}{c}{ NN Absoluto $^{2}$} & \multicolumn{2}{c}{$\%$} & \multicolumn{2}{c}{ TOTAL } \\
& Matutino & Noturno & Matutino & Noturno & No $^{\circ}$ & $\%$ \\
\hline Sim & 21 & 40 & 63,60 & 59,70 & 61 & 61,00 \\
Não & 12 & 27 & 36,40 & 40,30 & 39 & 39,00 \\
TOTAL & 33 & 67 & 100,00 & 100,00 & 100 & 100,00 \\
\hline
\end{tabular}

Fonte: Pesquisa direta com questionário. UEL/94 
Para acentuar o problema, outras informações demonstram que $59 \%$ dos calouros trabalham; e trabaIham mais que 8 horas por dia. É lógico que, em termos de alunos/matutino e alunos/noturno, a situação é in- vertida. No matutino tem-se $24,2 \%$ que trabalham, enquanto no noturno esse número chega a $76,1 \%$. Os que trabalham, de modo geral são assalariadas alocados no setor de serviços. (Tabelas 5, 6, 7 e 8)

TABELA 5 - Situação profissional do calouro de economia

\begin{tabular}{lcccccc}
\hline Situação & \multicolumn{2}{c}{ № Absoluto } & \multicolumn{2}{c}{$\%$} & \multicolumn{2}{c}{ TOTAL } \\
& Matutino & Noturno & Matutino & Noturno & № & $\%$ \\
\hline Trabalha & 8 & 51 & 24,20 & 76,10 & 59 & 59,00 \\
Não trabalha & 25 & 16 & 75,80 & 23,90 & 41 & 41,00 \\
TOTAL & 33 & 67 & 100,00 & 100,00 & 100 & 100,00 \\
\hline
\end{tabular}

Fonte: Pesquisa direta com questionário. UEL/94

TABELA 6 - Horas de trabalho do calouro de economia

\begin{tabular}{lcc}
\hline Horas de trabalho & No Absoluto & $\%$ \\
\hline Menos de 6 horas & 4 & 4,10 \\
Seis horas & 6 & 6,10 \\
Oito horas & 32 & 32,70 \\
Mais de oito horas & 15 & 15,30 \\
Não trabalha & 41 & 41,80 \\
Não respondeu & 2 & - \\
TOTAL & 100 & 100,00 \\
\hline
\end{tabular}

Fonte: Pesquisa direta com questionário. UEL/94

TABELA 8 - Setor onde trabalha o calouro de economia

\begin{tabular}{lcc}
\hline Setor & № Absoluto & $\%$ \\
\hline Agricultura & 1 & 1,10 \\
Indústria & 11 & 11,60 \\
Oito horas & 32 & 32,70 \\
Mais de oito horas & 15 & 15,30 \\
Não trabalha & 41 & 41,80 \\
Não respondeu & 2 & - \\
TOTAL & 100 & 100,00 \\
\hline
\end{tabular}

Fonte: Pesquisa direta com questionário. UEL/94
TABELA 7 - Categoria do trabalhador calouro de economia

\begin{tabular}{lcc}
\hline Categoria & № Absoluto & $\%$ \\
\hline Assalariado & 50 & 50,50 \\
Dono do próprio negócio & 8 & 8,10 \\
Não trabalha & 41 & 41,40 \\
Năo respondeu & 1 & - \\
TOTAL & 100 & 100,00 \\
\hline
\end{tabular}

Fonte: Pesquisa direta com questionário. UEL/94

Refletindo-se sobre a tabela anterior, verifica-se o grande percentual de universidades que não responderam aos questionários, e localizar a região onde não se obteve nenhuma resposta, a região norte. Este fato privou a pesquisa de elementos representativos dessa região. Convém, no entanto, destacar que as regiões sul e sudeste foram as que, relativamente, apresentaram maiores informações, e, em termos gerais de dependência administrativa, as federais colaboraram mais intensamente.

O levantamento dividiu-se em dois pontos. O primeiro, caracterização do docente que leciona introdução à economia, e o segundo, o seu conhecimento didático-pedagógico para realizar a sua função.

Em termos da UEL, a tradição é o revezamento de docentes que se responsabilizam pela cadeira introdutória, não existindo pré-requisitos essenciais para assumir a disciplina, pelo contrário, na maioria das vezes foi tratada por professores que iniciam a carreira universitária. Deve-se admitir, no entanto, que um esforço vem sendo dispendido para modificar esse estado de coisas desde a implantação do colegiado de cur- 
TABELA 9 - Demonstrativo das universidades públicas, estaduais e federais que oferecem o curso de economia, segundo a região e subordinação administrativa - 1994/95

\begin{tabular}{|c|c|c|c|c|c|c|}
\hline \multirow{2}{*}{$\begin{array}{l}\text { Região e } \\
\text { subordinação } \\
\text { administrativa }\end{array}$} & \multicolumn{2}{|c|}{$\begin{array}{l}\text { Responderam à } \\
\text { pesquisa }\end{array}$} & \multicolumn{2}{|c|}{$\begin{array}{l}\text { Não responderam } \\
\text { à pesquisa }\end{array}$} & \multicolumn{2}{|c|}{ TOTAL } \\
\hline & № & $\%$ & № & $\%$ & № & $\%$ \\
\hline Região Norte & - & - & 05 & 100 & 05 & 100 \\
\hline Pública Federal & - & - & 05 & 100 & 05 & 100 \\
\hline Pública Estadual & - & - & - & - & - & - \\
\hline Região Nordeste & 05 & 27,7 & 13 & 72,3 & 18 & 100 \\
\hline Pública Federal & 04 & 22,2 & 08 & 44,5 & 12 & 66,7 \\
\hline Pública Estadual & 01 & 5,5 & 05 & 27,8 & 06 & 33,3 \\
\hline Região Centro-Oeste & 01 & 20 & 04 & 80 & 05 & 100 \\
\hline Pública Federal & 01 & 20 & 03 & 60 & 04 & 80 \\
\hline Pública Estadual & - & - & 01 & 20 & 01 & 20 \\
\hline Região Sudeste & 05 & 35,7 & 09 & 64,3 & 14 & 100 \\
\hline Pública Federal & 03 & 21,4 & 06 & 42,9 & 09 & 64,3 \\
\hline Pública Estadual & 02 & 14,3 & 03 & 21,4 & 05 & 35,7 \\
\hline Região Sul & 04 & 44,4 & 05 & 55,6 & 09 & 100 \\
\hline Pública Federal & 03 & 33,3 & 02 & 22,2 & 05 & 55,5 \\
\hline Pública Estadual & 01 & 11,1 & 03 & 33,4 & 04 & 44,5 \\
\hline TOTAL & 15 & 29,4 & 36 & 70,6 & 51 & 100,00 \\
\hline
\end{tabular}

Fonte: Pesquisa direta com questionários enviados através dos Correios.

sos em 1992.

No periodo em que se deu a pesquisa, dois professores, economistas graduados na UEL, ministravam aulas para a disciplina de princípios de economia, sendo que um deles estava há mais de 10 anos na carreira universitária, mestre, e um recém-graduado, colaborador. Apesar da carga horária contratual ser integral, apenas um participava de projetos de pesquisa e extensão, estando o outro docente dedicando-se apenas às atividades em sala de aula em função de atividades profissionais fora da universidade. Ainda sobre isso, com exceção de um professor que ensina a economia introdutória há mais de 10 anos, o outro professor tinha pouca experiência com a disciplina.

Dos professores das outras instituições analisadas, todos são economistas, sendo que a grande parte deles se graduaram em instituições públicas, são do sexo masculino e têm mais de 35 anos de idade. Mais, $80 \%$ trabalham somente em uma instituição de ensino, sendo que $93,3 \%$ lecionam há menos de 15 anos no magistério superior.

Quanto à titulação, 66,7\% dos docentes possuem, no mínimo, o mestrado, prevalecendo as áreas de teoria econômica e desenvolvimento econômico. Indagados sobre a classe a que pertencem, obteve-se a resposta de que $92,9 \%$ são no mínimo assistentes.

A carga horária contratual de $93,3 \%$ dos entrevistados é de 40 horas semanais, sendo que $60 \%$ possuem dedicação exclusiva. Colocando a idéia de que o curso de introdução à economia deve ter caráter antecipatório $(64,3 \%$ dos professores assim atestam), devendo ter o docente uma grande dedicação em vista da visão geral que tem de ter do curso como um todo, as características elencadas são relevantes.

A carga horária de ensino de $80 \%$ dos professores é de 12 horas semanais ou menos. Em vista disso, pode-se concluir que existem horas para o desenvolvimento de outras atividades acadêmicas como projetos de pesquisa, ensino, extensão e outras. Isso se reflete no fato de $78,6 \%$ dos docentes realizarem pesquisa e $53,3 \%$ participarem em projetos de ensino. No entanto, a maior parte dos docentes, $60 \%$, não participa de atividades de extensão universitária. Esse último dado pode refletir o distanciamento entre a universiade e a comunidade e levantar a necessidade de buscar um estreitamento maior da academia com as empresas, fábricas, comércio, institutos de pesquisa, associações, órgãos da União, estados e municípios para que, através de parcerias, as informações possam ser geradas em maior quantidade e com maior qualidade e, mais 
importante, possam chegar ao conhecimento de um maior número de pessoas.

E quando se fala em conhecimento didático-pedagógico dirigido à matéria? Na UEL, os professores não receberam, (e nem recebem) institucionalmente, orientação didático-pedagógica para ingressarem na carreira docente, e quando o fazem é por iniciativa própria. Dos professores que estavam em atividades na disciplina, apenas um recebe orientação, e ainda assim, esporadicamente. De forma geral utilizam estratégias de ensino concentradas em aulas expositivas e, secundariamente, seminários e trabalhos escritos.

Quando se encontra o conhecimento de outras instituições, a realidade não é diferente nesse aspecto; o estudo detectou que $86,6 \%$ dos professores não receberam nenhuma orientação didático-pedagógica antes de assumir a cadeira introdutória, e, quando o fez foi por iniciativa própria. No decorrer do tempo nessa função também não recebem orientação $(73,3 \%)$ e se o fazem, por iniciativa própria, é esporadicamente. Em $73,3 \%$ dos casos verifica-se a inexistência de programas institucionais de apoio didático-pedagógico, e quando existe, em $26,7 \%$ deles a sistemática de apoio é facultativa.

A partir do pouco conhecimento pedagógico e praticamente sem orientação, os docentes escolhem as estratégias de ensino e avaliação convencionais, destacando-se as aulas expositivas (com utilização de quadro de giz e retroprojetor), com avaliação realizada por prova e trabalhos escritos.

Insistiu-se na solicitação de detalhamento quanto às técnicas de ensino empregadas nas 15 instituiçōes que haviam remetido as primeiras respostas, obtendo-se apenas 04 (quatro) respostas. Destas, chamou a atenção a experiência do Prof. Duilio de Ávila Berni, pelo cuidado com que tratou a questão. $O$ professor em dois trabalhos enviados, "como fazer um plano de ensino: aplicação à introdução à economia" - 1993, e "plano de estudos de introduçăo à economia" - 1994, discute como fazer um plano de ensino para introdução à economia utilizando esta última como elemento do concreto passado. Em seu plano, exemplificativamente, há um avanço para a conscientizaçăo da importância da metodologia de ensino aplicada à disciplina introdutória, onde constam, além de outros, atividades desenvolvidas como tarefas de investigação econômica de pontos específicos, listas de exercícios com a introdução do elemento "frater" (aluno que corrige a lista e aplica o conceito ao companheiro de turma) e uma pequena monografia para debater sobre a atualidade, ilustrando as potencialidades e aplicabilidade da teoria econômica. (BERNI, 1993, 1994)
Se, por um lado, as técnicas convencionais não são muito estimuladoras e a busca de alternativas para atuar em sala de aula (ou fora dela) é imperiosa, por outro lado, esbarra-se no perfil do calouro de economia da UEL. O desafio é agendar basicamente metodologias de ensino que incentivem o aluno a continuar o curso que escolheu, e ao mesmo tempo pensar o problema distintamente para os dois turnos, variando a sua intensidade mas mantendo a qualidade do curso.

É necessário que os docentes, principalmente os que exercem atividades na disciplina de princípios de economia do noturno, apropriem-se do conhecimento que vem sendo produzido sobre a relação entre educação e trabalho para adequar o ensino ministrado às necessiades do aluno trabalhador, que, de modo geral, se mostra com mais maturidade e experiência de vida. Faz-se mister também que o professor também perceba que antes de ser um profissional da economia, na universidade ele é um profissional de ensino, responsável pela condução pedagógica da disciplina e que, portanto, há um espaço que é fundamentalmente seu na busca da melhoria da açäo didática dirigida ao curso de introdução à economia.

No curso de economia da UEL, está-se gradativamente iniciando uma discussão sobre a necessidade da orientação pedagógica para as diversas disciplinas que integram o currículo de graduação. Embora o alvo seja os iniciantes na carreira universitária, de forma facultativa, entende-se que deve se estender para os demais docentes. Como dito, isto exige um trabalho de conscientização e disposição por parte dos docentes, o que requer um espaço de tempo para executá-lo a contento.

Adiantando-se para responder a todos esses desafios, este estudo destaca a importância dos projetos de ensino para trazer opções metodológicas que venham das aspirações dos alunos e, por conseqüência, signifiquem um novo rumo para o desenvolvimento do curso. Propostas como oficinas de produção de conhecimento econômico, laboratórios, visitas às empresas e outros precisam ser agilizadas. A criação de um programa interno de apoio didático ao curso de economia da UEL vindo através de cursos e mini-cursos, em conjunto com o departamento de educação, aliado a um grupo de estudos e coordenação acadêmica por série, dariam suporte a essas idéias.

\section{CONSIDERAÇÕES FINAIS}

Para concluir este trabalho, estabelecer-se-ão comentários gerais que derivaram da investigação. $O$ primeiro diz respeito à urgência de uma política 
departamental no sentido de despertar nos alunos e professores o interesse pelo assunto em questão. Embora se costume ter a idéia de dirigir professores auxiliares de ensino para a disciplina de principios/introdução à economia, ficou nítida nas escolas que se interessaram pelo tema respondendo aos questionários, a grande incidência de professores com titulação mínima de mestre e o que é melhor, com tempo integral e dedicação exclusiva à universidade além de experiência na disciplina.

Assim, considera-se salutar que apenas as pessoas preparadas tanto teórica como pedagogicamente tomassem a responsabilidade de ministrar o curso introdutório, afinal, a primeira (boa) impressão é que deve permanecer. Ao grupo de docentes constituído para esse fim seria oferecido uma dimensão da realidade discente, obtida através do perfil do calouro, permitindo que as questões do ensino-aprendizagem assumissem foros mais experientes e qualificados para a discussão. A criação da semana acadêmica contribuiria muito para que o evento se frutificasse.

As propostas já mencionadas de criação de um programa interno de apoio didático do curso de economia (propin) e do grupo de estudos e coordenação aca- dêmica por série (geca), também iria de encontro ao objetivo de desenvolvimento da política de estímuto e o adestramento didático dos professores.

O segundo comentário trata de outros mecanismos que podem ser ativados visando a qualidade da bibliografia utilizada e a coerência interdisciplinar. Cursos de reciclagem de curta duração e intercâmbios com outras universidades, precisam ser promovidos periodicamente, bem como a intensificação da monitoria acadêmica e o desenvolvimento de projetos de ensino. Este último poderia se iniciar com o intuito de atingir as séries iniciais, a exemplo do projeto "universidade-realidade" executado sob a coordenação da autora desse artigo, para depois se estender às séries seguintes.

Finalmente, deve-se orientar o tratamento específico para o estudante que trabalha. Isto não significa menos qualidade, mas sim, através da admissão da especificidade, buscar alternativas viáveis para a melhoria desta qualidade, porque se por um lado o trabalho fora da universidade reduz o tempo dispendido em atividades extra-sala, por outro, a maturidade e a experiência que possuem, em sua maior parte no setor de serviços, devem ser exploradas, tornando-as um pretexto para o salto do conhecimento econômico.

SOUZA, S.C.I. de The teaching of economics principles: a contribution. Semina: Ci. Sociais/Humanas, Londrina, v. 17, n. 3, p. 329-337, Sep. 1996.

ABSTRACT: The aim of this work is to provoke a reflection about the teaching of economics principles, through the analysis of two fundamental elements that constitute the initial process of the economist formation. Beginning for the reality of UEL, it discuss about the outline of the economics freshmen and characterizes the teacher who transmits the economic introducing knowledge, searching concretes experiences at the schools of economics in this country. Concludes that teachers who teach introduction to economics should be previously contemplated for a theorical and pedagogical preparation, for a deep knowledge about the reality students dimension, and for the programs and integrated actions developed for this object.

KEY-WORDS: Economics teaching; economics principles; economics freshmen; economics teacher.

\section{REFERÊNCIAS BIBLIOGRÁFICAS}

BASTOS, VL. A disciplina introdução à economia como introdução ao estudo da realidade econômica. Brasília, UnB, [198_..].

BERNI, D. Como fazer um plano de ensino: aplicação à introdução à economia. Porto Alegre, UFRGS, 1993.

\section{Plano de estudos de introduçăo à economia.} Porto Alegre, UFRGS, 1994 .

BUAINAIN, A.M. Notas sobre o ensino de introdução à economia. São Paulo, [198_]

CASTRO, N.J. A disciplina de introduçăo à economia na FEA UFRJ. Rio de Janeiro, UFRJ, 1988.
CONSELHO FEDERAL DE EDUCAÇÃo. Resolução n. 11, de 26 de junho de 1984. Brasília, MEC, 28 jun. 1984.

GALBRAITH, J.K. A economia ao alcance de quase todos. 4 ed. São Paulo, Pioneira, 1992.

GANEN, A. O curso de introdução à economia em discussão: algumas consideraçóes metodológicas. Rilo de Janeiro, Universidade Federal Fiuminense, [198_]

LEMME, M.C. Curso de introdução à economia: uma experiência. Rio de Janeiro, UFRJ, 1986.

VERSIANI, F.R. O novo curriculo mínimo de economia e sua aplicação. Literatura econômica, Săo Paulo, v. 6, n. 3, p. $411-428$, jun. 1984 